\title{
THE IMPLEMENTATION OF PATIENT NAVIGATION TO IMPROVE MAMMOGRAPHY COVERAGE AND ACCESS TO BREAST CANCER CARE IN RIO DE JANEIRO
}

\author{
Trazendo a navegação de pacientes para melhorar a cobertura mamográfica \\ e o acesso aos cuidados de câncer de mama no Rio de Janeiro
}

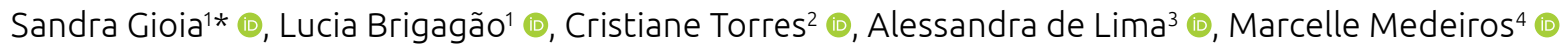

\section{ABSTRACT}

This study evaluates the Patient Navigation Program (Programa de Navegação do Paciente - PNP), which was introduced to a community in the municipality of Rio de Janeiro. The objectives were: to establish the viability of the PNP in this context; identify barriers to mammogram screening; and ensure mammogram coverage for 70\% of women recruited between 50 and 69 years old. From March to September 2018, 678 women with an average age of 58 years old were recruited from the Andaraí community. Follow-up was performed through the patient browser (PB), by telephone, email and text messages. Twelve percent of women refused to participate in the PNP for cultural reasons. The main barriers reported by women were: systematic problems with health care programming (100\%), financial problems (64\%), concerns about communicating with medical staff (58\%), fear (44\%), and social support (14\%). The PNP obtained $100 \%$ satisfaction, and the mammogram coverage rate goal was exceeded, reaching $88 \%$. The PN promoted an increase in the rate for mammogram coverage, aided in the transmission of quality information, reduced individuals' fear of mammography, and facilitated access to breast health care.

KEYWORDS: breast neoplasms; mammography; patient navigation; primary health care.

\section{RESUMO}

Este estudo avalia a introdução do Programa de Navegação do Paciente (PNP) em uma comunidade do município do Rio de Janeiro. Os objetivos são: estabelecer a viabilidade do PNP nesse contexto; identificar as barreiras ao rastreamento mamográfico; e assegurar cobertura mamográfica de 70\% das mulheres recrutadas entre 50 e 69 anos. De março a setembro de 2018, foram recrutadas 678 mulheres com idade média de 58 anos da comunidade do Andaraí. O acompanhamento foi realizado pelo navegador de pacientes (NP) por telefone, e-mail e mensagens de texto. Doze por cento das mulheres recusaram-se a participar do PNP por razões culturais. As principais barreiras relatadas pelas mulheres foram: problemas do sistema com programação de cuidados de saúde (100\%), problemas financeiros (64\%), preocupações relacionadas à comunicação com a equipe médica (58\%), medo (44\%) e apoio social (14\%). Foram obtidos $100 \%$ de satisfação com o PNP, e a meta de taxa de cobertura mamográfica foi superada, atingindo o percentual de $88 \%$. O NP promoveu aumento na taxa de cobertura mamográfica, auxiliou na transmissão de informações de qualidade, reduziu o medo da mamografia e facilitou o acesso aos cuidados de saúde da mama.

PALAVRAS-CHAVE: neoplasias da mama; mamografia; navegação de pacientes; atenção primária à saúde.

1State Department of Health - Rio de Janeiro (RJ), Brazil.

${ }^{2}$ Gynecology unit, Hospital Federal do Andaraí - Rio de Janeiro (RJ), Brazil.

${ }^{3}$ Breast radiology unit, Hospital Federal do Andaraí - Rio de Janeiro (RJ), Brazil.

${ }^{4}$ Fundação Laço Rosa - Rio de Janeiro (RJ), Brazil.

*Corresponding author: sandra.gioia@gmail.com

Conflict of interests: Nothing to declare.

Received on: 06/22/2019. Accepted on: 10/13/2019 


\section{INTRODUCTION}

In Brazil, breast cancer is the most common cancer and the leading cause of cancer death among women, with 14,206 deaths in 2013 and 59,700 new cases estimated for 2019. Barriers to cancer care access in Brazil lead to delays in diagnosis and treatment with the consequent result of the cancer reaching advanced stages and then producing a high mortality rate among patients ${ }^{1}$.

Delayed diagnosis and treatment of breast cancer leads to the presentation of more advanced stages and poor survival outcomes $^{2}$. The delay can be attributed to two reasons: a patient delay and a healthcare system delay. The health care delay - the time between a first consultation and when treatment is begun - is significantly longer in middle- and low-income countries compared to high-income countries ${ }^{3}$. In Brazil, a patient with breast cancer takes an average of 6-7 months to receive a definitive diagnosis after the first consultation with a doctor ${ }^{4}$. A study from Rio de Janeiro found that the average time from first consultation to a diagnosis is 6.5 months $^{5}$.

In low- and middle-income countries, long delays in diagnosis and treatment often lead to a clinical progression of the disease: in the United States, $60 \%$ of breast cancers are diagnosed at an early stage of the disease, while in Brazil these are only $20 \%$ of the diagnoses ${ }^{4}$. In a study of 87,969 Brazilian women with breast cancer, $53.5 \%$ were considered to be at an advanced stage ( $\geq$ IIB stage $)^{6}$, and in another study cohort, $78.8 \%$ of women were at stage II-IV ${ }^{7}$. The latest report from the Global Breast Health Initiative highlights the importance of guidelines developed for early detection, diagnosis and treatment of breast cancer, ultimately with the goal of reducing mortality ${ }^{8}$.

Even in Brazil, staging and survival statistics vary according to sociodemographic characteristics, such as type of health insurance. There are two types of insurance in the Brazilian health system: insurance obtained through the public system Sistema Único de Saúde (SUS) - or through private providers 9 . About $75 \%$ of Brazilians receive coverage exclusively through SUS, and despite progress in universal healthcare coverage across the country, large disparities affecting cancer care remain. Women treated in the public system have a more advanced disease than women in the private sector, and women in the public sector have worse disease-free and overall survival rates (which can be partly attributed to a longer delay and advanced stages at the time of diagnosis $)^{9}$.

The main method of breast cancer screening is mammography. Recognizably, a public health measure with proven effectiveness in screening for breast cancer requires mammography to be accessible to the population ${ }^{10}$. Screening for breast cancer may be opportunistic when the test is offered to women seeking healthcare facilities, or population-based when the test is directed toward women in the target population who are recruited for periodic screening. In developed countries, coverage of at least $70 \%$ of the target population can reduce mortality by $20-30 \%$ in women over 50 . The model adopted by Brazil is opportunistic screening ${ }^{11}$.

Breast cancer control requires access to mammography and strategies for diagnosis and treatment of suspected cases, ensuring the quality of these services ${ }^{12}$. In the document of technical parameters for the screening of breast cancer from the National Cancer Institute José Alencar Gomes da Silva (INCA), an ideal parameter of one mammograph per 240 thousand inhabitants has been proposed. This is considering that the equipment is working properly. But the existence of a mammogram machine does not in itself provide that the exam will take place, since the procedure requires adequate conditions for operation, continuous maintenance of the equipment, availability of supplies, trained staff and quality assurance. Increasing the supply of exams for greater coverage of the target population depends on sufficient numbers of mammograms, geographic distribution of equipment, and productivity ${ }^{12}$.

With this in mind, it is important to identify the availability of mammograph machines, as well as the regional distribution of equipment and examinations performed ${ }^{13}$. This is even more important for the state of Rio de Janeiro, which has been identified with the highest gross incidence rate of female breast cancer in the country, estimated at 92.90 new cases per 100,000 women for the year $2019^{1}$.

According to one study, the distribution of mammograms in Rio de Janeiro, especially the mammograms from SUS, even though they were not equal, followed the percentage distribution of the population according to state regions ${ }^{13}$. However, even if mammograms were not lacking in comparison with the national parameter, they were not necessarily utilized regularly. In the state of Rio de Janeiro, the estimated population for 2016 was $16,635,996$, which would require 68 machines to be in accordance with the national parameter ${ }^{13}$. Both the total number of mammographs in use (546) and the total number available for SUS (142) for the state of Rio de Janeiro, in 2012, surpassed oversupply, according to the national parameter. Therefore, according to all of the points analyzed in all of the regions, the state of Rio de Janeiro did not have an equipment deficit ${ }^{13}$. However, a study conducted to estimate mammogram coverage in opportunistic screening performed by SUS in Brazil, its regions and its Federal Units, found that in Rio de Janeiro, the coverage rate was $14.6 \%$ with 150,994 tests performed when 1,034,567 were expected ${ }^{14}$.

Despite the high frequency of this kind of tumor, in Rio de Janeiro there is no structure that allows women assisted by SUS, a system that covers the vast majority of Brazilian women, to be guaranteed decent care that is focused not only on treatment, but also on prevention and early diagnosis. International experience has shown that organized screening has better results and lower costs. In countries that have implemented effective screening programs that reach the target population, and have high quality tests and appropriate treatment, breast cancer 
mortality has been decreasing. Evidence of the impact of screening on mortality from this type of cancer justifies the adoption of cancer screening as a public health policy, as recommended by the World Health Organization (WHO) ${ }^{15}$.

In this context, the Patient Navigation Program (PNP), "a coordinated process of individualized care offered to patients in order to overcome barriers in access to timely and quality care in complex health systems," can potentially enable organized screening of breast cancer ${ }^{16}$. The Patient Navigation Program (PNP) is designed to address health disparities and reduce obstacles for timely cancer treatment. Patient Navigators (PNs) are trained healthcare professionals who facilitate the handling of patients in the healthcare system, helping them to overcome institutional, socioeconomic and personal barriers to access. It also provides services such as scheduling diagnostic and follow-up appointments, facilitating referrals from the health system, and coordinating communication between patients and health professionals. PNs help patients receive timely medical care and reduce care delays and the rate of missed follow-up appointments ${ }^{16}$.

Despite the great success of the PNP among underserved populations in the United States, this program has not been widely studied in middle- and low-income countries ${ }^{17}$. Patients in these countries face structural barriers that are similar to those faced by underprivileged US patients. Due to lack of awareness, fragmentation and complexity of health systems, low socioeconomic statuses, cultural barriers, and limited funding and human resources in public health institutions, these patients often do not receive timely cancer care ${ }^{18}$. The PNP has already proven to be a valuable tool for addressing these barriers in the United States and could potentially be adapted and deployed to do the same in middle- and low-income countries such as Brazil ${ }^{17}$.

\section{OBJECTIVES}

The overall objective of the study was to promote adherence to breast cancer screening with mammograms as recommended by the Ministry of Health, with the help of PNs. As secondary objectives, the study proposed to:

- establish the viability of the PNP in this context;

- identify barriers to mammogram screening;

- ensure mammogram coverage for $70 \%$ of women recruited between 50 and 69 years old, as considered acceptable by the WHO.

\section{METHODOLOGY}

\section{Study Location}

The study was conducted at the Family Health Strategy of the Odalea Firmo Dutra Family Clinic, which opened in February 2018 and is located in the Program Area (PA) 2.2 of Grande Tijuca,
Rio de Janeiro. This clinic has health professionals who coordinate, support, analyze, promote and execute health actions in the area that includes the Andaraí and Grajaú neighborhoods, and encompasses a population in need that has not been assisted for many years.

There are eight Family Health Teams with eight doctors, eight nurses and 32 community agents working in the Andaraí region. The PNs accompanied the work of registering the target population for mammograms.

\section{Patient Navigator}

\section{Patient Navigator Eligibility Criteria}

- Social worker with knowledge of the National Regulation System (Sistema Nacional de Regulação - SISREG) of the municipality and the state (SER) of Rio de Janeiro.

- Experience with breast cancer patients.

- Availability to work with the PNP designed for Rio de Janeiro.

\section{Patient Navigator Responsibilities}

- Guide the patient through the health system.

- Help the patient fill out insurance documentation.

- Guide the patient to perform clinical and radiological examinations and timely treatment.

- Identify local resources and support available to the patient, including transportation allowances, childcare resources, etc.

- Help the patient schedule consultations at Family Health and referral centers.

- Remind the patient about upcoming appointments.

- Facilitate communication between the patient and health professionals.

- Make sure the information provided to the patient has been clearly understood by the patient and help answer any of their follow-up questions.

\section{Patient Population}

\section{Inclusion Criteria}

- Women with no complaints of palpable breast lesions (asymptomatic) aged 50 to 69 years old.

- Assistance in the public sector for consultation in the Family Health Strategy.

\section{Exclusion Criteria}

- Women with no personal documents.

- Women with private health insurance.

- Women in need of supportive care (prognosis of survival of less than 6 months).

- In the terminal phase of some other disease (prognosis of survival of less than six months). 
- Women experiencing homelessness.

- Women with a history of drug abuse or alcoholism.

- Women suffering from major psychotic disorders or uncontrolled psychiatric disorders.

- Women with cognitive disabilities.

- Imprisoned women.

\section{Study Metrics}

The study metrics were divided into two parts - principal questionnaires and a psychosocial interview:

- Main questionnaires for collecting general information on patient characteristics and barriers to health care. These questionnaires were designed for this study and include:

(i) patient population data, as measured by the enrollment questionnaire, in order to collect information on the barriers reported by the patients;

(ii) clinical reference information, measured through an information form, to record relevant clinical information;

(iii) patient satisfaction, as measured by a patient satisfaction survey, to ensure that the patients and their families consider the navigation to be useful.

- Psychosocial interview to collect more detailed information about patients' illnesses and their struggles.

The success threshold for this study was that at least $70 \%$ of the recruited patients had up-to-date mammograms.

\section{RESULTS}

An initial listing of 678 asymptomatic women aged 50 to 69 years old was provided by the community clinic's community health workers (CHA), and came with the telephone number and name of the Family Health Team to which they each belonged.

Of the 678 women listed, 181 were excluded from the interview recruitment process for the following reasons:

- 79 women reported not having to have a mammogram or their partner forbade a mammogram or clinical examination of the breasts (cultural reasons). This group represented $12 \%$ of the population found;

- 102 women were symptomatic, under 50 or over 69 years old and had a family history of breast cancer. This group represented $15 \%$ of the population involved that underwent a mammography and a clinical examination of the breasts. The youngest woman was 31 years old and the oldest was 76. In this group, six women $(0.9 \%)$ were identified with a palpable breast lump and a mammography radiographic category of 4 or 5 from the Breast Imaging-Reporting and Data System $\left(\right.$ BI-RADS $\left.{ }^{\circledR}\right)$. These cases were referred for diagnostic confirmation, in which the breast biopsy revealed to be a malignant neoplasm.
497 women were recruited to participate in the PNP. Table 1 shows the radiological classification of the mammograms of these women. All women with a category 0 or 3 mammography BI-RADS ${ }^{\circledR}$ underwent a breast ultrasound that came back normal. In the end, the $88 \%$ mammogram coverage rate was achieved.

Of the women recruited, 100 were randomly invited to participate in interviews to compose the study metrics (Table 2). The PNP obtained 100\% satisfaction among the patients. The main impressions reported by patients about the PNP were: ease of access to breast care (41\%), reduced fear of mammography (25\%), promotion of quality health information (19\%) and need for continuation to benefit other women in the community and other communities (15\%). All patients indicated one to six barriers to obtaining breast health care, with an average of three barriers. The main barriers found are presented in Chart 1.

Table 1. Radiological category of mammograms of the women recruited for the study ( $\mathrm{n}=497)$.

\begin{tabular}{l|c} 
Radiological Category (RC) & $\mathbf{N}(\%)$ \\
\hline RC 0 & $32(6 \%)$ \\
\hline RC 1 & $123(25 \%)$ \\
\hline RC 2 & $330(67 \%)$ \\
\hline RC 3 & $12(2 \%)$ \\
\hline
\end{tabular}

Table 2. Characteristics of the patients who answered the main questionnaires $(n=100)$.

\begin{tabular}{|c|c|}
\hline Variables & Value \\
\hline Family risk for breast cancer & $23 \%$ \\
\hline Have you ever had a mammogram? & $90 \%$ \\
\hline \multicolumn{2}{|l|}{ Radiological Category (RC) } \\
\hline $\mathrm{RC} 0$ & $7 \%$ \\
\hline $\mathrm{RC} 1$ and $\mathrm{RC} 2$ & $84 \%$ \\
\hline $\mathrm{RC} 3$ & $9 \%$ \\
\hline Smoking & $23 \%$ \\
\hline Regular Physical Activity* & $30 \%$ \\
\hline \multicolumn{2}{|l|}{ BMI } \\
\hline Normal weight & $29 \%$ \\
\hline Overweight & $37 \%$ \\
\hline Obesity Grade I & $27 \%$ \\
\hline Obesity Grade II & $6 \%$ \\
\hline Obesity Grade III & $1 \%$ \\
\hline Comorbidities** & $66 \%$ \\
\hline Death*** & 2 cases \\
\hline
\end{tabular}

* Main activities: walking, water aerobics and dancing at least twice a week: ** main comorbidities: systemic arterial hypertension and diabetes mellitus; *** cause of death: acute myocardial infarction; BMI: body mass index. 


\section{DISCUSSION}

The Patient Navigation Program (PNP) is designed to address health disparities and reduce obstacles for timely cancer treatment. PNs are trained healthcare professionals who facilitate the handling of patients in the healthcare system, helping them overcome institutional, socioeconomic and personal barriers to access. It also provides services such as scheduling diagnostic and follow-up appointments, facilitating referrals from the health system, and coordinating communication between patients and health professionals. PNs help patients receive timely medical care and reduce care delays and the rate of missed follow-up appointments ${ }^{19}$.

The pioneering PNP was in the Harlem district of New York in the 1990s, and it was designed to improve timely access to cancer care among low-income, low-educated patients. The program achieved impressive results, improving the five-year survival rate for breast cancer from 39 to $70 \%$ in the target population ${ }^{19}$. Further studies have proven that PNP can improve time to diagnosis and treatment resolution, reduce missed follow-up rates, minimize health disparities, and increase patient awareness ${ }^{20}$. The PNP has increased attendance at screening appointments by providing patient-oriented education, making them more likely to attend all regular medical appointments compared to those not in the program ${ }^{21}$. Another important benefit is that it significantly shortens the time between lesion detection and diagnosis ${ }^{22}$. In addition, navigator results include lower rates of missed appointments, increased screening rates, and better equity for vulnerable patients ${ }^{23}$.

The Global Cancer Institute has already proposed an action agenda aimed at successfully implementing the PNP in middleand low-income countries ${ }^{17}$ and this same agenda could be applied to the Brazilian context to guide the implementation of this program in the country ${ }^{17}$, possibly helping to guarantee adherence to mammogram screening and integrate services in the country's health system. One of the objectives of the implementation of the PNP is to influence health authorities and hospital administrators to integrate PNs into existing health system infrastructure ${ }^{17}$. Thus, policy makers are involved in PNPs, from the planning to implementation stages. This is important so that the PNP is not seen as an additional expense to health systems, but rather as an opportunity for a reallocation of funds, focusing on the use of scarce resources in prevention and early treatment rather than in the final stage of the disease ${ }^{17}$.

For the early detection program and the treatment of breast cancer to be efficient and effective in the near future, political will, cooperation of the medical entities and civil society involved in the discussion, and consistent and regular allocation of financial resources are fundamental. However, there will only be progress with modern management, with well-defined goals and indicators, which are constantly audited and evaluated, otherwise it is possible to be lost in good intentions ${ }^{24}$.

Limitations of guideline implementation strategies in lowand middle-income countries may be related to issues such as scarcity or poor distribution of health professionals and inadequate availability of medical products and supplies, which are clearly not restricted to the provision of services related to breast health ${ }^{18}$. Similarly, the issues of access to services and the ability (or inability) to receive funding go beyond the reach of this project because they are truly systemic ${ }^{18}$.

Each location needs to plan and customize its PNP. The main barriers were identified and effectively minimized. The PNP achieved $100 \%$ satisfaction and an $88 \%$ mammogram coverage rate, exceeding initial expectations of the $70 \%$ coverage rate. The PN's work in the Andaraí community was based on three

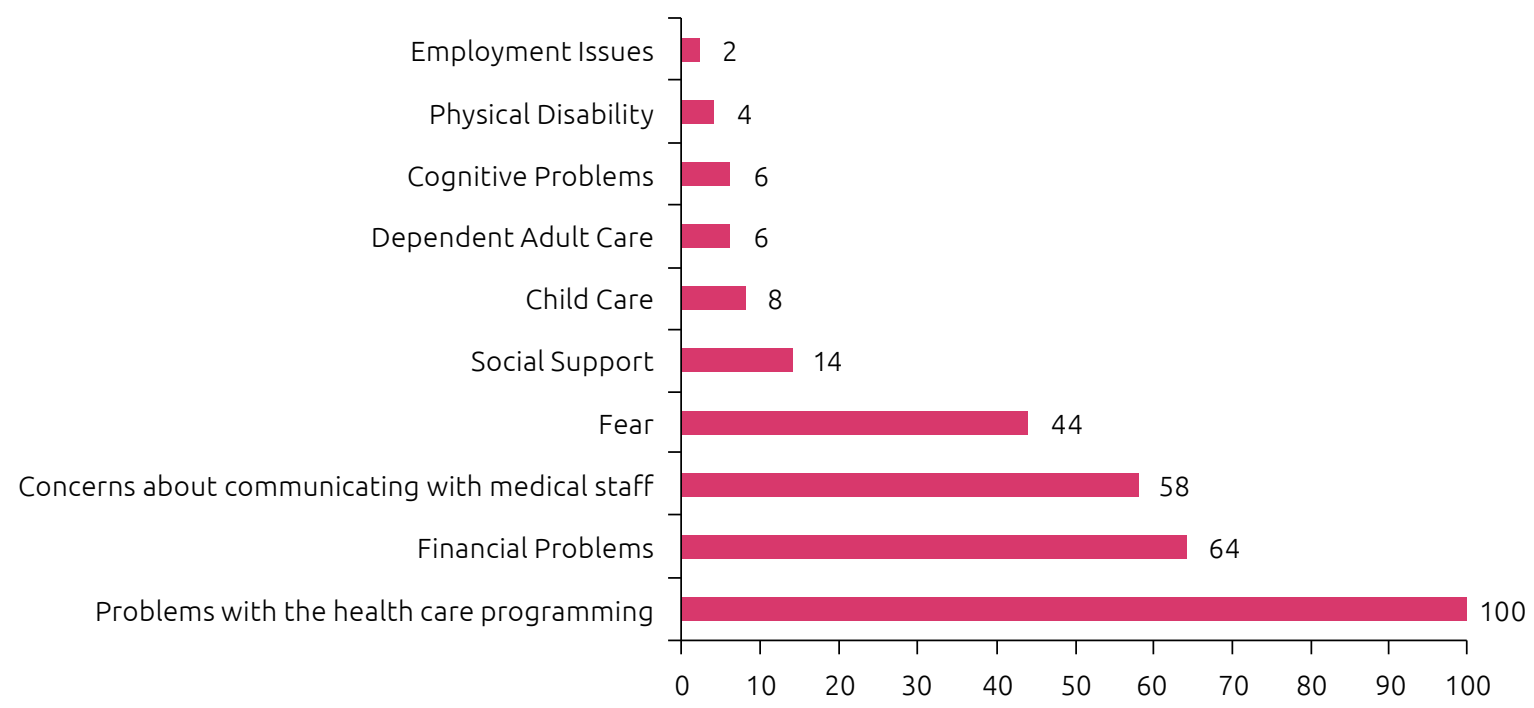

Chart 1. Barriers reported by patients for breast health care in primary care in the Andaraí community ( $\mathrm{n}=100 \%)$. 
pillars: informed woman; trained primary care health professional; and commitment to breast health care. PNs are the link between patients and the health services, promoting individualized care and assistance in overcoming potential barriers (economic, social, cultural, religious, logistical, and those related to the health system) to breast health ${ }^{16}$.

The health teams were observed to have low autonomy with regard to addressing the barriers that women face ${ }^{24}$. The need for local leadership, who specialize in breast diseases and believe in the importance of PNs for improving care for women becomes critical for the continuity of a PNP in primary care ${ }^{24}$. Six women with early stage breast cancer were identified in this group, and they were properly referred for treatment.

The family clinic needs to address the lifestyle change of the target population due to the high incidence of comorbidities, physical inactivity and obesity, known risk factors for breast cancer. Because of the high incidence of family risk for breast cancer in this population, genetic counseling and specific management for the high-risk population need to be further explored ${ }^{25}$. It was observed that patients and health professionals from the Andaraí family clinic have difficulty in identifying risk factors and specific actions related to breast health. In practice, the engagement of breast cancer specialists in primary health care is necessary to optimize the training of health professionals and patients ${ }^{25}$.

\section{CONCLUSIONS}

The PNP for breast cancer in the Andaraí community proved viable in the SUS context. The main barriers to mammography in this community were identified and minimized. The PN promoted an increase in the rate for mammogram coverage, aided in the transmission of quality information, reduced individuals' fear of mammography, and facilitated access to breast health care. The PNP obtained $100 \%$ satisfaction among the patients and was successful, with a mammogram coverage rate of $88 \%$.

\section{ACKNOWLEDGMENTS}

Renascença Clube, Global Cancer Institute, Instituto Avon and the Sociedade Brasileira de Mastologia - Regional Rio de Janeiro.

\section{REFERENCES}

1. Instituto Nacional de Câncer José Alencar Gomes da Silva. Estimativa 2018: Incidência de câncer no Brasil [Internet]. Brasil: INCA; 2018 [acessado em 3 abr. 2019]. Disponível em: https://www.inca.gov.br/sites/ufu.sti.inca.local/files// media/document//estimativa-incidencia-de-cancer-nobrasil-2018.pdf

2. Richards MA, Westcombe AM, Love SB, Littlejohns P, Ramirez AJ. Influence of delay on survival in patients with breast cancer: A systematic review. Lancet. 1999;353(9159):1119-26. https://doi.org/10.1016/s0140-6736(99)02143-1

3. Unger-Saldãna K. Challenges to the early diagnosis and treatment of breast cancer in developing countries. World J Clin Oncol. 2014;5(3):465-77. https://doi.org/10.5306/wjco.v5.i3.465

4. Goss PE, Lee BL, Badovinac-Crnjevic T, Strasser-Weippl K, Chavarri-Guerra Y, St Louis J, et al. Planning cancer control in Latin America and the Caribbean. Lancet Oncol. 2013;14(5):391-436. https://doi.org/10.1016/S14702045(13)70048-2

5. Rezende MC, Koch HA, Figueiredo J de A, Thuler LCS. Factors leading to delay in obtaining definitive diagnosis of suspicious lesions for breast cancer in a dedicated health unit in Rio de Janeiro [in Portuguese]. Rev Bras Ginecol Obstet. 2009;31(2):7581. http://dx.doi.org/10.1590/S0100-72032009000200005

6. Medeiros GC, Bergmann A, Aguiar SS, Thuler LCS. Determinants of the time between breast câncer diagnosis and initiation of treatment in Brazilian women [in Portuguese]. Cad Saúde Pública. 2015;31(6):1269-82. http:// dx.doi.org/10.1590/0102-311X00048514
7. Barros AF, Uemura G, de Macedo JL. Interval for access to treatment for breast cancer in the Federal District, Brazil [in Portuguese]. Rev Bras Ginecol Obstet. 2013;35(10):458-63. http://dx.doi.org/10.1590/S0100-72032013001000006

8. Anderson BO, Yip CH, Smith RA, Shyyan R, Sener SF, Eniu A, et al. Guideline implementation for breast healthcare in low-income and middle-income countries: Overview of the Breast Health Global Initiative Global Summit 2007. Cancer. 2008;113(Supl. 8):2221-43. https://doi.org/10.1002/cncr.23844

9. Lee BL, Liedke PE, Barrios CH, Simon SD, Finkelstein DM, Goss PE. Breast cancer in Brazil: Present status and future goals. Lancet Oncol. 2012;13(3):e95-e102. https://doi.org/10.1016/ S1470-2045(11)70323-0

10. Marinho LAB, Cecatti JG, Osis MJD, Gurgel MSC. Knowledge, attitude and practice of mammography among women users of public health services. Rev Saúde Pública. 2008;42(2):200-7. http://dx.doi.org/10.1590/S0034-89102008005000006

11. OliveiraEXG,PinheiroRS,MeloECP,CarvalhoMS.Condicionantes socioeconômicos e geográficos do acesso à mamografia no Brasil, 2003-2008. Ciênc Saúde Coletiva. 2011;16(9):3649-64. http:// dx.doi.org/10.1590/S1413-81232011001000002

12. Kuschnir R, Chorny AH. Redes de atenção à saúde: contextualizandoodebate.CiêncSaúdeColetiva.2010;15(5):230716. http://dx.doi.org/10.1590/S1413-81232010000500006

13. Brasil. Ministério da Saúde. Portaria no 1.101, de 12 de junho de 2002. Estabelece os parâmetros de cobertura assistencial no âmbito do Sistema Único de Saúde - SUS. Diário Oficial da República Federativa do Brasil. 2002; Seção 1:36. 
14. Freitas-Junior R, Rodrigues DCN, Corrêa RS, Peixoto JE, Oliveira HVCG, Rahal RMS. Contribuição do Sistema Único de Saúde no rastreamento mamográfico no Brasil, 2013. Radiol Bras. 2016;49(5):305-10. http://dx.doi.org/10.1590/01003984.2014.0129

15. World Health Organization. International Agency for Research on Cancer. World Cancer Report 2008. Lyon: World Health Organization; 2008.

16. Battaglia TA, Bak SM, Heeren T, Chen CA, Kalish R, Tringale S, et al. Boston Patient Navigation Research Program: The impact of navigation on time to diagnostic resolution after abnormal cancer screening. Cancer Epidemiol Biomarkers Prev. 2012;21(10):164554. https://doi.org/10.1158/1055-9965.EPI-12-0532

17. Bukowski A, Gioia S, Chavarri-Guerra Y, Soto-Perez-de-Celis E, St. Louis J, Nogueira-Rodrigues A, et al. Patient Navigation to Improve Access to Breast Cancer Care in Brazil. J Glob Oncol. 2016;3(5):433-7. https://doi.org/10.1200/JGO.2016.006726

18. Harford J, Azavedo E, Fischietto M. Guideline Implementation for Breast Healthcare in Low- and Middle-Income Countries. Cancer. 2008;113(Suppl. 8):2282-96.http://doi.org/10.1002/ cncr.23841

19. FreemanHP.Patient navigation:A community-centered approach to reducing cancer mortality. J Cancer Educ. 2006;21(Supl. 1):S11-S14. https://doi.org/10.1207/s15430154jce2101s_4
20. Freund KM, Battaglia TA, Calhoun E, Darnell JS, Dudley DJ, Fiscella K, et al. Impact of patient navigation on timely cancer care: The Patient Navigation Research Program. J Natl Cancer Inst. 2014;106(6):dju115. https://doi.org/10.1093/jnci/dju115

21. Jabson JM. Treatment summaries, follow-up care instructions, and patient navigation: Could they be combined to improve cancer survivor's receipt of follow-up care? J Cancer Surviv. 2015;9(4):692-8. https://doi.org/10.1007/s11764-015-0444-0

22. Raich PC, Whitley EM, Thorland W, Valverde P, Fairclough D. Patient navigation improves cancer diagnostic resolution: An individually randomized clinical trial in an underserved population.Cancer Epidemiol Biomarkers Prev.2012;21(10):162938. https://doi.org/10.1158/1055-9965.EPI-12-0513

23. Percac-Lima S, López L, Ashburner JM, Green AR, Atlas SJ. The longitudinal impact of patient navigation on equity in colorectal cancer screening in a large primary care network. Cancer. 2014;120(13):2025-31. https://doi.org/10.1002/cncr.28682

24. Ohl ICB, Ohl RIB, Chavaglia SRR, Goldman RE. Public actions for control of breast cancer in Brazil: integrative review. Rev Bras Enferm. 2016;69(4):746-55. http://dx.doi. org/10.1590/0034-7167.2016690424i

25. Gioia S. Why is breast cancer early detection important? Mastology. 2017;27(3):173-5. http://dx.doi.org/10.5327/ Z259453942017EDIT273 